\title{
EVIDÊNCIA E ESPECULAÇÃO: “A ORIGEM" DO FUTEBOL NO RIO DE JANEIRO (1898-1902)
}

\author{
EVIDENCE AND SPECULATION: THE "ORIGIN" OF FOOTBALL IN RIO DE \\ JANEIRO (1898-1902)
}

EVIDENCIA Y ESPECULACIÓN: "EL ORIGEN" DEL FÚTBOL EN RIO DE JANEIRO (1898-1902)

Victor Andrade Melo*

\begin{abstract}
Palavras chave:
História.

Esportes.

Futebol.

Rio de Janeiro.

Resumo: Há décadas, têm sido usuais os debates sobre "a origem" do futebol no Brasil. Não poucas vezes marcadas por disputas identitárias e por tendências celebratórias, tais discussões são um indicador da intensa presença social dessa prática. Neste artigo, discutem-se algumas evidências de experiências com o futebol que ocorreram no Rio de Janeiro entre os anos de 1898 e 1902. Para alcance do objetivo, como fontes, foram utilizados periódicos publicados na cidade, especialmente o The Rio News. Para interpretação do material, tiveram-se em conta as sugestões de Luca (2005), considerandose 0 que foi veiculado como representações relacionadas ao perfil do cronista e/ou jornal/revista. Questionando a natureza de sustentação de algumas afirmações sobre os primórdios do futebol no Rio de Janeiro, inferiu-se que, entre 1898 e 1902, foram realizados os primeiros jogos em diferentes esferas, se estruturou um pioneiro calendário e começou a se conformar um campo que iria rapidamente se estabelecer.
\end{abstract}

\section{Keywords:}

History.

Sports.

Soccer.

Rio de Janeiro.

Abstract: For decades, there have been discussions about the "origin" of football in Brazil. Often marked by identity disputes and celebratory inclinations, such discussions indicate the strong social presence of that sport. This article discusses some evidence of football experiences that took place in Rio de Janeiro between 1898 and 1902. Newspapers and magazines published in the city were used as sources, especially The Rio News. To interpret the material, suggestions of Luca (2005) were taken into account, considering what was published as representations related to writers' and/or publications' profile. By questioning the basis of some statements about the early days of football in Rio de Janeiro, we infer that, between 1898 and 1902, the first matches were held in different spheres, a pioneer calendar was structured, and a field started to emerge that would quickly be established.

Palabras clave:

Historia.

Deportes.

Fútbol.

Rio de Janeiro.
Resumen: Durante décadas han sido usuales los debates sobre "el origen" del fútbol en Brasil. No pocas veces marcadas por disputas de identidad y tendencias de celebración, tales discusiones son un indicador de la intensa presencia social de este deporte. En este artículo se discuten algunas evidencias de experiencias con el fútbol que tuvieron lugar en Río de Janeiro entre los años 1898 y 1902. Para alcanzar ese objetivo, fueron usados como fuentes periódicos publicados en la ciudad, especialmente el The Rio News, editado en inglés entre 1874 y 1901. Para la interpretación del material, se han tenido en cuenta las sugerencias de Tania Regina de Luca (2005), considerando lo que se publicó como representaciones relacionadas a las características del cronista y del periódico. Cuestionando la naturaleza de algunas afirmaciones sobre los primeros momentos de fútbol en Río de Janeiro, se percibió que, entre 1898 y 1902, se realizaron los primeros juegos en diferentes ámbitos, se estructuró un calendario pionero y se comenzó a conformar un campo que vendría a establecerse rápidamente.
*Universidade Federal do Rio de Janeiro. Rio de Janeiro, RJ, Brasil. E-mail: victor.a.melo@uol.com.br

Recebido em: 05-04-2016 Aprovado em: 28-10-2016

(c) (i) () Licence 


\section{INTRODUÇÃO}

Há décadas, têm sido usuais os debates sobre "a origem" do futebol no Brasil. Não poucas vezes marcadas por disputas identitárias de naturezas diversas (manifestas na defesa de quem seria o "pioneiro") e por tendências celebratórias (bastante visíveis em efemérides, quando se cultua nostalgicamente o passado), tais discussões são um indicador da intensa presença social dessa prática esportiva'.

Personagens como Charles Miller e Oscar Cox, entre outros, são constantemente rememorados por seus feitos. A narrativa épica tem semelhanças argumentativas. Tendo conhecido e se apaixonado pelo futebol em localidades mais "civilizadas", em seu retorno a sua terra de origem, trouxeram materiais esportivos e o desejo de organizar a prática, convencendo outros interessados, enfrentando dificuldades, ao fim superadas com grande esforço. Graças a eles, nessa representação, teria começado a gloriosa trajetória do ludopédio no Brasil.

Essa abordagem, muito comum em livros de grande circulação (aqueles dedicados ao grande público), chegou mesmo, em alguns momentos, a ecoar no âmbito acadêmico. Todavia, é nessa esfera que se tem contestado mais intensamente essa narrativa ${ }^{2}$. Ao aprofundar e ampliar os olhares sobre o futebol, coloca-se em xeque essa busca desenfreada pelas "origens". Em linhas gerais, alguns estudos conclamam a perceber que o desenvolvimento da modalidade foi mais múltiplo e complexo, não emergindo de um único polo³.

Algumas dessas considerações, pelo menos em parte, parecem ter chegado ao público não acadêmico interessado no futebol, que obviamente não interrompeu e nem necessariamente deveria ter interrompido sua forma de abordar o esporte. Isto é, não se deve esperar que esse tipo de olhar para o objeto siga as mesmas diretrizes de uma investigação acadêmica. Ainda assim, certas hipóteses aventadas pelos pesquisadores acerca das "origens" da modalidade no país passaram a ser incorporadas em determinadas releituras.

Um bom exemplo dessa tendência é o verbete "História do futebol do Rio de Janeiro" do Wikipédia4. No item "Primórdios", sugere-se que marinheiros ingleses teriam praticado a modalidade na Glória, em $1874^{5}$. Vale citar que, durante parte do século XIX, desde pelo menos 1865 , foi comum que se disputassem jogos de críquete entre equipes de britânicos que moravam na capital ${ }^{6}$ e de embarcações da Grã-Bretanha que aportavam na Baía de Guanabara (MELO, 2014, MELO, 2016).

A despeito de ser uma versão plausível, não foram encontradas evidências concretas de que jogos de futebol tenham feito parte desses encontros, bem como nenhuma referência específica à partida citada. Há que se ter em conta que o cotidiano da colônia britânica pouco aparecia nos jornais de grande circulação. Mas nada há também nos periódicos publicados em inglês (The Anglo-Brazilian Times, The British and American Mail, Rio Commercial Journal,

1 Muitos sítios na internet, bem como alguns livros, abordam o assunto. Em muitas ocasiões, são iniciativas de apaixonados pelo esporte ou por seus clubes de coração.

2 Desde os anos 1980, tem se estruturado um campo de estudos ao redor do futebol, investigações desenvolvidas a partir de um diálogo mais contundente com o arcabouço das Ciências Humanas e Sociais. Para um olhar sobre tal conformação, entre outros, ver Santos e Drumond (2013).

3 Ver, por exemplo, MASCARENHAS, Gilmar. A bola nas redes e o enredo do lugar: uma geografia do futebol e de seu advento no Rio Grande do Sul. Tese (Doutorado em Geografia) - Programa de Pós-Graduação em Geografia Humana, Universidade de São Paulo, 2001 e Santos (2010). 4 HISTÓRIA..., 2016.

5 Os trabalhos acadêmicos que reproduzem essa ideia em geral dialogaram com as considerações de Mazzoni (1950).

6 Neste artigo, denominar-se-ão de colônia britânica e britânicos não somente os que, vivendo no Brasil, nasceram no Reino Unido (que, em função do uso mais comum, neste texto será tratado como Grã-Bretanha), mas todos que possuíam laços com essa nação, inclusive os descendentes nascidos em nosso ou outros países. 
The Rio News, The Brazilian Review). Isto é, tal possibilidade tem sido especulada em diversas ocasiões, mas não consta que haja sobre ela maiores indícios.

A seguir, no verbete, sugere-se que se deve ter em conta a criação do Foot Rink Club, em 1881, por alunos do Colégio Paixão, de Petrópolis, que por sua vez teria sido um dos primeiros a inserir o futebol no cotidiano escolar graças à atuação de um de seus professores. Essa informação, da mesma forma que a anterior, carece de maior precisão. Basta dizer que a citada agremiação era dedicada às corridas a pé, que se tornaram bastante apreciadas nas décadas finais do século XIX?.

Já há muitos anos se argumenta que alguns colégios, especialmente aqueles que tinham alguma forma de relação com a Grã-Bretanha, estiveram entre os pioneiros a apresentar a modalidade aos brasileiros ${ }^{8}$. No verbete, a propósito, sugerem-se mais duas ocorrências semelhantes: em 1883, em Nova Friburgo, e 1896, também em Petrópolis. Em todos esses casos, todavia, sabe-se pouco do que ocorria no cotidiano.

Outra informação apresentada na Wikipédia é que, em 1893, ingleses que trabalhavam na Leopoldina Railway e em bancos britânicos disputaram jogos em "um capinzal que se localizava na rua Paissandu". De novo, percebe-se uma inconsistência. O que há em fartura divulgado nos jornais da colônia são partidas de críquete entre as empresas citadas (bem como envolvendo fábricas têxteis), algo que se tornou mais comum a partir de $1895^{\circ}$. Em boa parte das vezes, tiveram lugar na sede do Rio Cricket Club, depois Club Brazileiro de Cricket, cuja sede se encontrava no logradouro citado.

O verbete sugere ainda que o escocês Tomas Donohoe teria apresentado o futebol quando trabalhou na instalação da Companhia Progresso Industrial de Bangu. A informação parece sustentada na obra de Clovis Molinari, que produziu um relato mais sofisticado, ainda que também carente de maior embasamento (isso é, a despeito da interessante argumentação, 0 autor não explicita suas fontes $)^{10}$.

Para concluir esse olhar sobre o verbete, citemos que informa que o primeiro jogo "oficial"11 do Rio de Janeiro teria sido realizado no dia 1ํ de agosto de 1901, promovido por Oscar Cox, no Rio Cricket and Athletic Association. Não encontrei evidências dessa partida nos jornais. Por que o The Rio News, que registrava muitos acontecimentos esportivos da colônia britânica, inclusive e notadamente os que ocorriam nessa agremiação, não fez menção a tal ocasião?

Em todos esses casos, duas questões merecem debate. A primeira é, em maior ou menor grau, de forma mais ou menos assumida, o trânsito de informações que se percebe entre duas diferentes instâncias de produção de conhecimento. Os fatos citados não raramente são reproduzidos em trabalhos acadêmicos sem um filtro adequado.

A segunda é a relevância desse conhecimento. Mesmo que todos os fatos citados possam ser comprovados, que importância, de fato, trazem para a melhor compreensão da presença do futebol na sociedade fluminense? Um exemplo. Em 1888, uma matéria narrou

\footnotetext{
7 Para mais informações, ver Melo (2009a).

8 Um dos pioneiros foi Marinho (1956)

9 Ver, por exemplo, The Rio..., 1895.

10 O livro Nós que somos banguenses está disponível em: <http://www.bangu.net/informacao/livros.php>. Acesso em: 28 mar. 2016.

11 O próprio termo "oficial", largamente utilizado em sítios e mesmo trabalhos acadêmicos, merece ser problematizado. Não há nada que sustente o uso de tal denominação para esse suposto primeiro jogo.
} 
detalhadamente um grande acontecimento social, um picnic oferecido pelo barão de Guahy na sua chácara da Rua Conde do Bonfim. Ao descrever os detalhes da festa, informou-se que se ofereceu aos convidados "jogos de críquete, futebol, quiles, péla, bola, salto, tiro ao alvo etc." (DIÁRIO..., 1888, p. 2).

Com isso, pode-se dizer que a sociedade fluminense já conhecia a modalidade? Seria um indício das "origens" da prática na cidade? Que importância teria no que tange à sua organização? A propósito, seria mesmo o que hoje se chama de futebol aquele divertimento citado na matéria?

A questão a responder é como, na transição dos séculos XIX e XX, um conjunto de ocorrências sobre as quais se podem obter indícios, mais do que fatos isolados, indicam a conformação de um novo costume, a gestação de um campo ao redor de uma prática. Tendo em conta essa expectativa, neste artigo pretende-se discutir algumas evidências ${ }^{12}$ de experiências com o futebol que ocorreram no Rio de Janeiro entre os anos de 1898 e 1902.

Nesses anos, se tornaram mais usuais notícias sobre a modalidade nos periódicos fluminenses. A partir de 1902, essas informações já se referem aos pioneiros clubes fundados. Assim, aborda-se um período de latência daquele que no futuro seria o mais popular esporte do Rio de Janeiro.

Para alcance do objetivo, como fontes foram utilizados periódicos publicados na cidade, especialmente 0 The Rio News. Para interpretação do material, tiveram-se em conta as sugestões de Tania Regina de Luca (2005), considerando-se o que foi veiculado como representações relacionadas ao perfil do cronista e/ou jornal/revista.

Vale, de pronto, destacar a peculiaridade do principal periódico utilizado. The Rio News foi editado em inglês entre os anos de 1874 e 1901. Seu intuito era ser porta-voz dos anglófonos (britânicos e estadunidenses) estabelecidos no Rio de Janeiro e em outras cidades brasileiras. Publicava pontos de vista e informações julgadas interessantes para as duas colônias (ROCHA, 2007). Os eventos esportivos estiveram entre os assuntos mais constantes.

O intuito deste estudo é tanto lançar um novo olhar para o futebol quanto refletir sobre a construção de sua história, sobre os desafios que se apresentam para os que pretendem investigar aquele que é considerado o esporte-rei em nosso país.

\section{UM CLUBE DE ANGLÓFONOS}

Nos anos 1860, encontravam-se em situação incômoda os britânicos que no Rio de Janeiro viviam. Desde a chegada da família real portuguesa, em 1808, gozavam de certos privilégios (reduzidos nos anos 1840) e tinham forte influência na economia, a princípio no comércio, posteriormente também na esfera industrial e financeira. Até mesmo por isso, com eles houve conflitos diversos tanto no âmbito governamental quanto no cotidiano. Naquela década, isso se acentuou com os problemas desencadeados pela Questão Christie (RICUPERO, 2011; BETHELL, 2012).

Se a colônia britânica já se caracterizava por manter certa distância da sociedade fluminense (FREYRE, 1977), a ocasião exigia ainda maior prudência, estimulando o fortalecimento 
de um costume inglês, já usual no Rio de Janeiro do momento (FONSECA, 2008), entabulado inclusive pelos oriundos da Grã-Bretanha na cidade estabelecidos - a criação de clubes.

No que tange ao esporte, nos anos 1850, foi criado o British Cricket Club (MELO, 2016). Em 1862, a partir dessa experiência, foi fundado, no bairro de Botafogo, o Rio Cricket Club. Essa agremiação se tornou um centro de encontros dos britânicos, um espaço para cultuar uma de suas tradições mais valorizadas, a prática de sports.

Essa intenção se potencializou quando o clube se transferiu para uma nova sede, localizada no bairro de Laranjeiras, na esquina de Rua Guanabara com Rua Paissandu, em frente ao Palácio Guanabara (Figura 1), um terreno alugado pelo Conde d’Eu. Durante décadas, nesse espaço se promoveram eventos de atletismo, partidas de tênis e jogos de críquete, disputados entre equipes da agremiação e de empresas e navios britânicos, entre times formados pelos associados, até mesmo com cricketers de São Paulo.

Figura 1 - Rua Paissandu vista de dentro do Palácio Guanabara. À direita, a sede do clube.

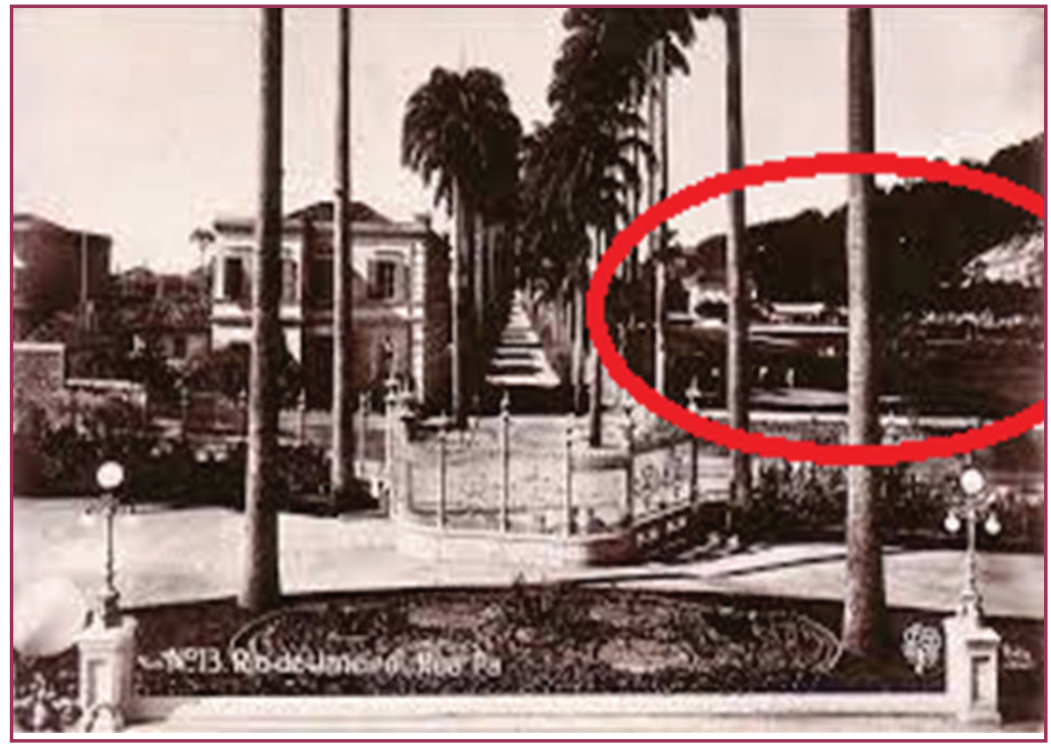

Fonte: Foto sem data, impressa em cartão postal da editora F. Manzieri de São Paulo.

Nos eventos de atletismo, se observava maior presença de brasileiros. Já os jogos de tênis e de críquete eram mais frequentados pelos membros da colônia, encarados como forma de celebração do ethos britânico. Vale citar que o Rio Cricket mantinha relações com agremiações como a British Subscription Library (dedicada à leitura, fundada em 1826) e o Clube das Laranjeiras, uma típica sociedade de gentlemen, de caráter mais social, criada em 1885 (MELO, 2016).

A chegada da República interferiu na dinâmica do Rio Cricket. Ainda que muitos britânicos estivessem ligados a causas mais liberais, como o abolicionismo, a colônia desfrutava de proximidade com a família imperial, além de sempre louvar seus monarcas, o que a tornava suspeita. Sentiram também as tensões relacionadas aos estrangeiros naqueles primeiros momentos do novo regime, explicitamente manifesta no que foi chamado de "grande naturalização" (todos que não se posicionassem em contrário passariam a ser considerados brasileiros).

O Rio Cricket enfrentou ainda outro problema. Com o fim da monarquia, o terreno de sua sede foi incorporado ao patrimônio nacional, administrado pelo Banco da República dos Estados 
Unidos do Brasil, que de pronto mais do que dobrou o aluguel. Depois de intensa negociação, ficou acordado que a agremiação manteria o espaço a título de empréstimo (MELO, 2016).

Em virtude dessa situação, passou a sofrer algumas intervenções, entre as quais dividir o espaço com uma nova agremiação, o Club Brazileiro de Cricket, que logo incorporaria a antiga sociedade. A despeito de haver, aparentemente, boas relações entre brasileiros e britânicos que integravam o quadro de associados, persistia um incômodo entre os segundos.

Em 1897, um grupo de lideranças da colônia britânica - entre os quais George Emmanuel Cox ${ }^{13}$, um sportsman admirado pela comunidade ${ }^{14}$-, com apoio de empresas inglesas no Rio de Janeiro estabelecidas, fundou em Niterói uma nova agremiação, o Rio Cricket and Athletic Association, que se tornou a preferida dos anglófonos estabelecidos no Rio de Janeiro e Niterói.

Um dos motivos alegados para tal decisão foi a instabilidade no que tange à posse da sede da Rua Paissandu (IORIO, IORIO, 2008). De fato, o Club Brazileiro de Cricket, em 1899 renomeado para Paysandú Cricket Club, enfrentou problemas diversos para manter o espaço. Não se deve, contudo, desprezar a possibilidade de os britânicos desejarem ter de novo uma agremiação mais exclusiva.

A despeito de certas dificuldades, as agremiações funcionaram intensamente naquela virada de século. Os calendários, lançados no início do ano, eram cumpridos na íntegra, sempre contando com bom público, majoritariamente de britânicos e estadunidenses. Não se confirmou a apreensão de que a criação de um novo clube dividisse e enfraquecesse a colônia, até mesmo porque havia associados que pertenciam a ambas (MELO, 2016).

A essa altura, o campo esportivo estava consolidado na cidade. Diferentes modalidades eram conhecidas: turfe, remo, corridas de bicicletas, provas de atletismo, entre outras. Muitas já eram as agremiações que promoviam com frequência seus eventos, envolvendo grande e variado público (MELO, 2009a, MELO, 2009b).

Nesse cenário, se percebe também uma consolidação e diversificação das modalidades praticadas pelos britânicos. Muitas foram as contendas de críquete entre equipes dos mais diversos perfis. Os jogos athleticos inglezes, concursos de corridas e saltos (em distância e em altura), disputados pela colônia já há muitos anos, continuavam mantendo bom espaço. Os torneios de tênis se tornaram mais usuais e organizados, destacando-se a constante participação de ladies. Os primeiros jogos de beisebol, protagonizados por estadunidenses, foram realizados. Partidas de futebol foram promovidas. Esse é o tema que nos interessa neste artigo.

\section{O FOOTBALL NO RIO DE JANEIRO DO SÉCULO XIX}

Não se pode dizer que o futebol era absolutamente desconhecido no Rio de Janeiro do último quartel do século XIX, ainda que poucas informações sobre o esporte circulassem nos jornais. Além da referência já citada na introdução (DIÁRIO..., 1888, p. 2), foram veiculadas algumas notícias sobre a modalidade em outros países, como França ${ }^{15}$ e Uruguai ${ }^{16}$. 
Muitas referências houve à Inglaterra, ressaltando-se o caráter britânico do futebol, considerado como exemplo de uma cultura que valorizava o esporte em geral ${ }^{17}$. Uma parte desses posicionamentos dizia respeito à educação. 0 Dr. Marcio Nery, por exemplo, sugeriu que a modalidade seria um dos principais exercícios físicos para trabalhar os membros superiores e inferiores, devendo, portanto, ser estimulada para os infantes (REVISTA..., 1896, p. 319). Teor semelhante se encontra num folhetim escrito por José Veríssimo, em que defendeu que se deveria dar mais atenção à Educação Física. Entre as práticas que julgava apropriadas, citou "jogos estrangeiros como o críquete, o futebol, o tênis, a cross, etc." (JORNAL DO BRASIL, 1891, p. 2).

Merece também referência o posicionamento do Dr. Eduardo Corrêa, pronunciado em uma das "Conferências populares": "A Inglaterra, como já tive ocasião de referir, marcha na vanguarda, e tão arraigados se acham já no espírito público os jogos atléticos ao ar livre que, pode-se dizer, não há um só inglês que não conheça e não tenha jogado o críquete, o futebol etc." (JORNAL DO COMMERCIO, 1899, p. 2).

Notícias mais relevantes foram encontradas mesmo no The Rio News. Uma primeira ocasião em que a modalidade apareceu com algum destaque foi na matéria que tratou da inauguração da sede do Rio Cricket and Athletic Association, em $1898^{18}$ (Figura 2). A cerimônia seguiu a tradição britânica e teve um grande maestro, aquele que há anos vinha liderando tantas iniciativas esportivas, George Cox. 0 intuito anunciado era oferecer um local apropriado para que se praticassem "os jogos que têm dado ossos, músculos e força, cérebro e saúde e hábitos comedidos para os súditos da Rainha em cada pedaço do planeta" (THE RIO..., 1898, p. 5).

Figura 2 - Sede do Rio Cricket Club

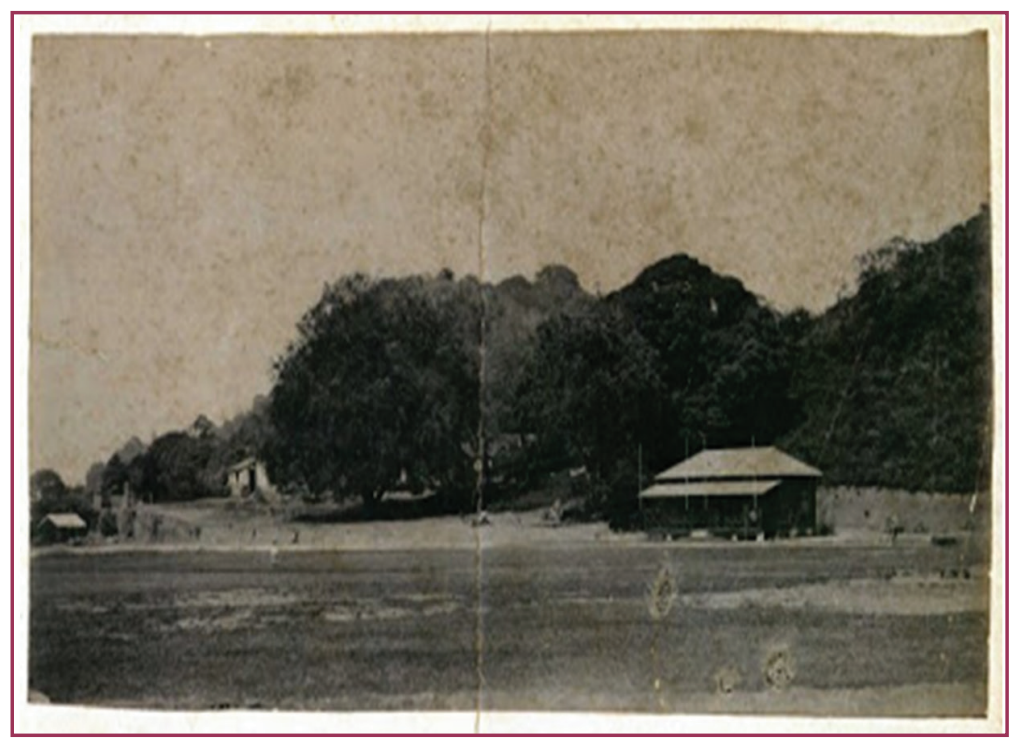

Fonte: REVISTA da Semana, 8 set. 1901, p. 574

Ao descrever de forma elogiosa cada parte da nova sede, o cronista sugeriu que não se desperdiçou "nem uma polegada do espaço, tudo sendo adaptado para as necessidades das equipes de críquete e futebol" (THE RIO..., 1898b, p. 5). Pouco mais de um mês depois, outro jornalista também registrou tal interesse: "o local está preparado convenientemente para diversos jogos, como sejam críquete, beisebol, futebol, tênis, corridas a pé e de velocípede,

17 Ver, por exemplo, Jornal..., 1894 e Gazeta..., 1899.

18 Uma noção da importância concedida à ocasião pode ser vista no fato de que a matéria ocupou quatro colunas do jornal, praticamente uma das suas quatro páginas. 
estando em vias de construção um tanque de natação" (JORNAL DO COMMERCIO, 1898, p. 2). Pelos detalhes da matéria, aparentemente alguém do clube ofereceu tal informação, mais um indício de que o ludopédio estava ao menos nos planos da direção da agremiação.

Percebe-se que o futebol era uma entre outras modalidades, não havendo nenhuma menção especial ou qualquer relevância a priori a ele concedida. Da mesma forma, integrava um movimento maior, do cenário esportivo como um todo, ajustado às dimensões que estavam sendo delineadas há mais tempo por práticas que vinham já se estruturando e estavam mais consolidadas.

De outro lado, por que o futebol, que até então não aparecera nas notícias dos clubes britânicos, fora citado de forma tão explícita? Ocasionalidade? Ou, ao contrário, trata-se de um indício de uma motivação que já estava sendo acalentada? Há uma evidência. Podem-se fazer algumas especulações.

Certamente a colônia britânica do Rio de Janeiro já tinha ouvido falar do futebol. Além do contato direto com a Grã-Bretanha, havia com os compatriotas de São Paulo constantes encontros, inclusive no âmbito esportivo. Desde 1875, foram periódicas as disputas de críquete entre equipes das duas cidades (MELO, 2016). A partir de 1898, inclusive se tornaram mais comuns no The Rio News notícias sobre os jogos do ludopédio disputados na capital paulistana.

A propósito, Charles Miller, um dos envolvidos com o desenvolvimento do futebol em São Paulo, em várias ocasiões esteve em terras fluminenses integrando equipes de críquete ${ }^{19}$. Em 1901, chegou-se a registrar seu agradecimento "aos clubes do Rio pela generosa hospitalidade" (THE RIO..., 1901, p. 5).

Pode-se também especular sobre a atuação de Oscar Cox, filho de George Cox que acabara de chegar de anos de estudo na Europa. Em 1897, seu nome já apareceu integrando uma equipe de críquete, a do London and River Plate Bank (THE RIO..., 1897, p. 4). Também esteve envolvido com as corridas e partidas de beisebol e tênis.

Aqui estar-se-ia se aproximando da história usual, a de que Oscar trouxe da Europa algum equipamento esportivo e o conhecimento sobre a nova modalidade. Nessa versão há um intervalo curioso. Se ele retornou ao Brasil em 1897, por que somente em 1901 teria organizado o primeiro jogo de futebol? Nesse ínterim, nada teria ocorrido? Nenhum outro membro da colônia britânica demonstrara interesse?

Deve-se chamar a atenção para um aspecto. Em muitas ocasiões, acadêmicas ou não, se consideram Miller e Cox como brasileiros (os primeiros do país a organizar iniciativas do futebol). Essa afirmação deve ser relativizada. Nasceram, sim, no Brasil, mas tinham profundos vínculos com a colônia britânica. É possível que se encarassem mais como parte dessa comunidade do que como nacionais stricto sensu.

Teriam ocorrido partidas de futebol naqueles momentos finais do século XIX? Há algumas evidências. No The Rio News publicou-se um comentário: "No Rio e outras partes do Brasil, esportistas britânicos têm jogado o críquete e o futebol durante o último mês. Esse é um país peculiar onde alguém pode praticar críquete e futebol indiscriminadamente, em qualquer época" (THE RIO..., 1898c, p. 8). No ano seguinte, ao comentar o calendário da temporada

19 Era capitão e um dos melhores jogadores de críquete da capital paulistana, além de costumeiro vencedor de corridas e bom jogador de rúgbi. Essas atividades estão registradas em várias notícias no The Rio News. 
de 1899, muito organizado no que tange ao críquete e ao tênis, um cronista expressou sua esperança de ver melhor estruturado o ludopédio (THE RIO..., 1899, p. 4).

É possível, assim, que alguns jogos de futebol tenham sido disputados, não deixando registros maiores por ainda não adotarem 0 modelo de organização que 0 críquete e 0 tênis tinham estabelecido. De outro lado, esses exemplos pressionavam os praticantes da modalidade a buscarem maior estruturação. $O$ fato é que apenas em 1901 há evidências mais seguras de que houve partidas no Rio de Janeiro.

A primeira delas não tinha relação direta com os clubes britânicos. Tratou-se de um festival esportivo promovido, no Campo de Santana, por um dos mais renomados professores de Educação Física da ocasião, Arthur Higgins ${ }^{20}$. Na programação - houve disputas de diferentes modalidades -, inseriu um jogo de futebol (GAZETA..., 1901, p. 3).

Não se pode afirmar que esse fato tenha tido qualquer desdobramento no forjar de uma maior estruturação da modalidade, ainda que seja mais um indicador de que ela progressivamente se apresentava à cidade. Passos mais significativos foram dados nas agremiações de críquete.

\section{O FOOTBALL NO RIO DE JANEIRO DO INÍCIO DO SÉCULO XX}

Como foi observado na introdução, nada foi encontrado sobre o tão citado jogo de $1^{0}$ de agosto de 1901. Todavia, em setembro do mesmo ano, o Correio da Manhã anunciou que, no dia 23, o The Rio Cricket sediaria uma disputa entre equipes com "as denominações de Brasil e Inglaterra" (CORREIO..., 1901, p. 3). Foram dois tempos de 20 minutos. Um empate em 1 x 1, com gols de Julio Moraes e Cawood Robinson. Oscar Cox e Malluloch foram os capitães.

A ter em conta a experiência do críquete, não se tratava de um "jogo internacional", mas sim entre descendentes de britânicos e brasileiros (provavelmente ligados ao clube do Rio de Janeiro) e britânicos propriamente ditos (possivelmente sócios da agremiação de Niterói). Esse tipo de jogo era comum nessas agremiações, curiosamente denominado Niggers $X$ Whites (os primeiros eram os nascidos na América do Sul, os segundos na Grã-Bretanha). Em setembro e outubro, várias partidas de futebol semelhantes foram disputadas nas duas cidades. 0 mesmo ocorreu nos anos seguintes.

Como não estão disponíveis para consulta edições do The Rio News dos meses de outubro e novembro, há poucas informações sobre esses jogos. É, contudo, uma decisão do Rio Cricket que nos permite perceber avanços no sentido de melhor estruturar a prática. 0 calendário para 1902 (Figura 3) previu partidas de futebol, juntamente com as de críquete e de tênis (THE BRAZILIAN..., 1902a, p. 130). Não se tratava exatamente de um campeonato, mas certamente de uma organização antes não observada.

Foram programadas cinco partidas entre os meses de abril e agosto. Uma delas era entre empresas britânicas (Banks x Coffee Houses). Duas eram as já realizadas no ano anterior Brazil x England. Os outros dois jogos eram de "selecionados" - Rio x Niterói e Rio x São Paulo. Claramente a inspiração era o modelo adotado pelo críquete.

20 Para mais informações sobre esse personagem, ver Souza (2011). A autora, inclusive, cita os nomes dos rapazes que se envolveram com as partidas de futebol, a maior parte de brasileiros, e não britânicos (com exceção de Victor Echegaray, que mantinha relação com o clube de críquete de Niterói). 
O fim do The Rio News dificulta a obtenção de informações sobre tais partidas. O The Brazilian Review, mais dedicado à economia, só eventualmente informava algo do cotidiano. Todavia, notícias começaram a ser mais veiculadas em jornais de grande circulação, outro indício de que a modalidade começava a se espraiar.

Figura 3 - Cricket no jornal

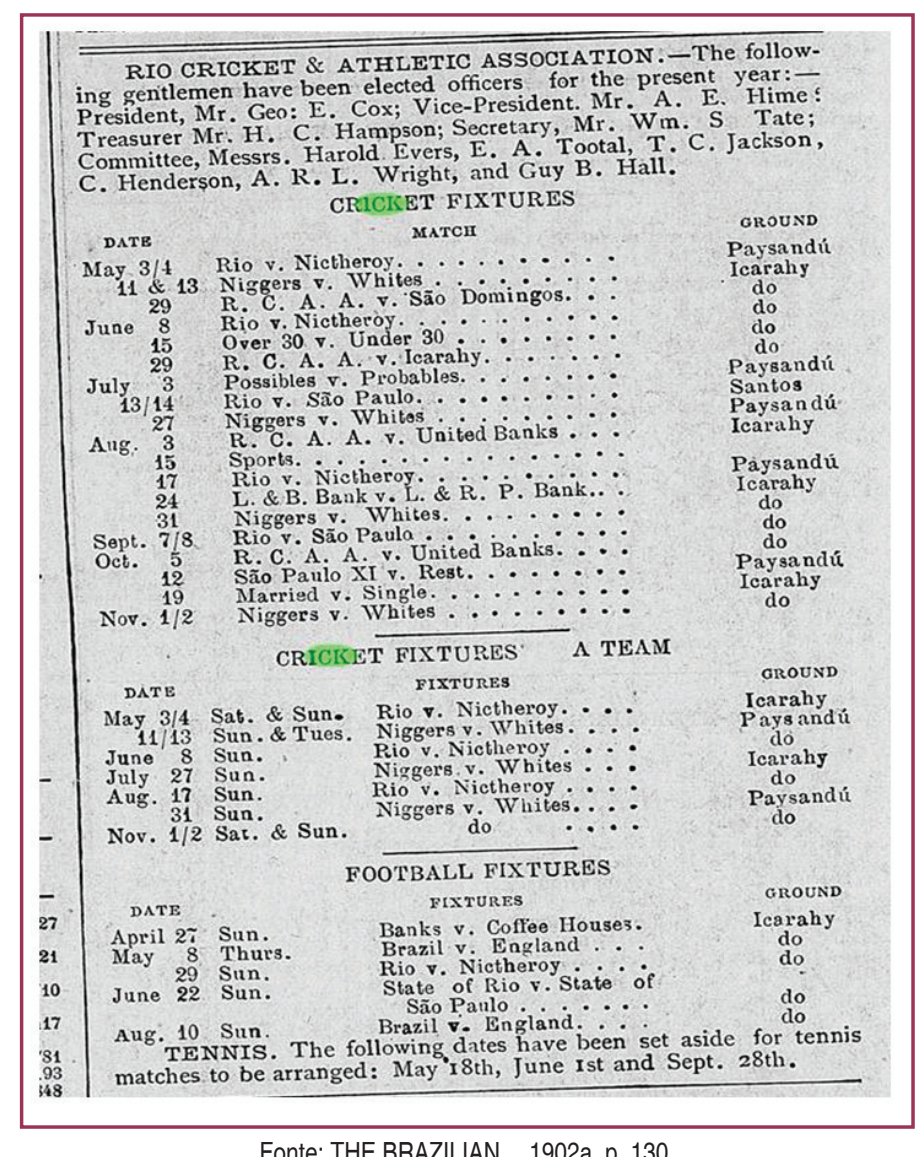

Fonte: THE BRAZILIAN...,1902a, p. 130.

O calendário teria sido cumprido? Há evidência de que pelo menos um jogo foi realizado, embora em data atrasada para conciliar com duas efemérides importantes, 0 aniversário do Rio Cricket e a celebração da coroação do rei britânico Eduardo VII. No mesmo dia foram realizadas provas de atletismo, como era usual nas comemorações anuais da agremiação (Figura 4).

Em 15 de agosto de 1902, mais um Brasil x Inglaterra foi realizado, tendo como capitães, respectivamente, Oscar Cox e A. R. L. Wright. Dessa vez, os jornais informaram até mesmo a formação das equipes ${ }^{21}$. Em $A$ Notícia publicou-se um relato entusiasmado do evento, segundo o cronista, marcado pela presença de grande público. Para ele, "o campo do Rio Cricket oferece bastante vantagem para a realização desse apreciado jogo de sport' (A NOTÍCIA, 1902, p. 2).

Vale dizer que a essa altura já estavam fundadas duas importantes agremiações. Em 12 de julho de 1902, anunciou-se a criação do "clube de jogos atléticos" Rio Football (CORREIO..., 1902a, p. 3), mais atuante do que se costuma considerar nos estudos sobre o futebol, notadamente porque um protagonismo maior é dado ao Fluminense Football Club, criado também no mesmo ano. 
Figura 4 - Provas de atletismo

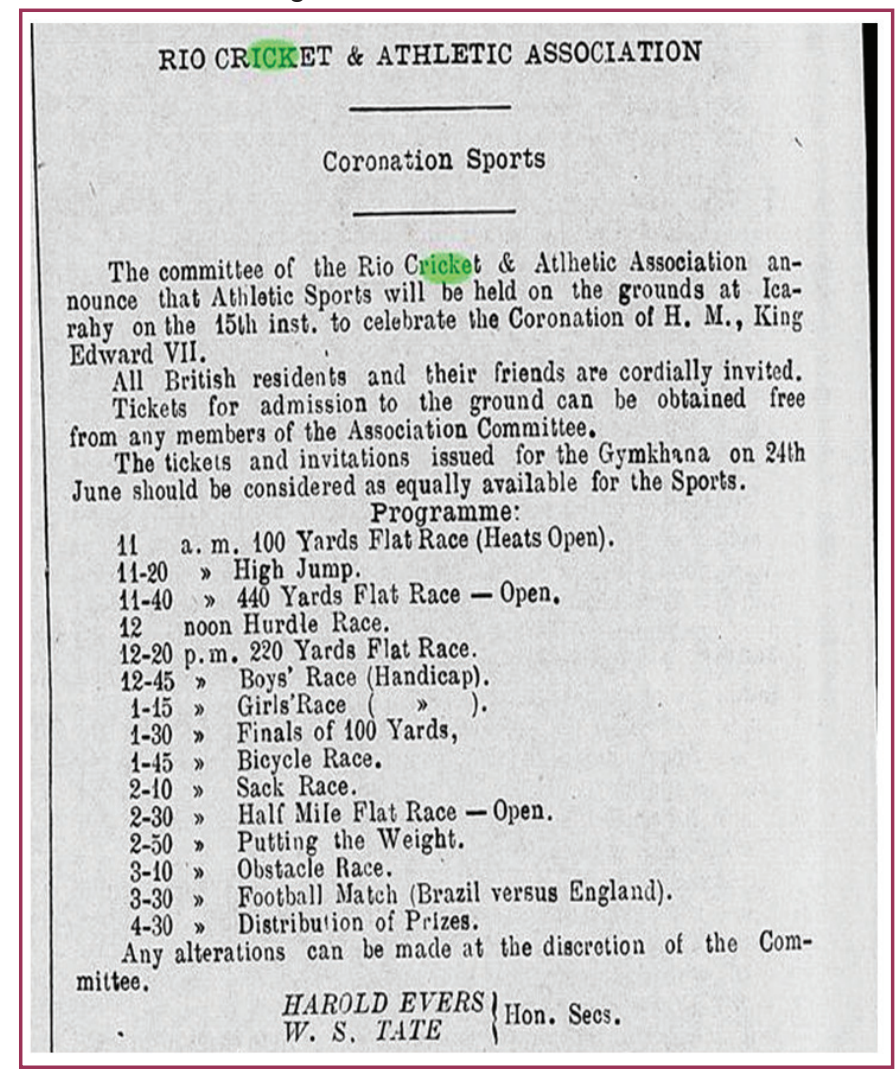

Fonte: THE BRAZILIAN ..., 1902, p. 392

A reunião de fundação do Rio Football foi realizada no Clube de Natação e Regatas, integrando a direção Eugenio Reis, Álvaro Teixeira de Castro, Américo Moraes, entre outros brasileiros. Era uma agremiação de nacionais e britânicos que tinha por pretensão se dedicar a outras modalidades, não somente ao ludopédio. Já no mês de agosto, promoveu um festival na Real Sociedade Clube Ginástico Português, evento que contou também com a participação do Natação e Regatas, Vasco da Gama e Boqueirão do Passeio (A NOTÍCIA, 1902b, p. 2). A festividade contou com exercícios ginásticos (triplo trapézio, acrobacia, barra fixa, argolas, paralelas) e combates de esgrima. Um cronista que descreveu minuciosamente 0 evento celebrou "a distinta plêiade de moços que compõem o número de sócios do Rio Football" (CORREIO..., 1902b, p. 3).

A agremiação procurava mesmo se inserir na dinâmica esportiva da cidade. Sua primeira sede foi uma sala na Federação Brasileira de Sociedades de Remo (SPORT..., 1902, p. 433), uma das mais importantes dos primórdios do esporte fluminense e nacional, entidade que congregava as agremiações de remo, mas também mantinha relações com as de outras modalidades (MELO, 2001). O ponto de contato era Emilio da Rocha Lima, diretor das duas entidades, bem como sócio do Club de Natação e Regatas.

Já o Fluminense Football Club foi criado alguns dias depois, 21 de julho de 1902, contando com brasileiros e também membros da colônia britânica. Ambos de alguma forma têm relação com os jogos realizados em 1901, inclusive alguns entre fluminenses e paulistas, excursões promovidas a exemplo do que ocorria com equipes de críquete.

Em setembro de 1902, houve um pioneiro match entre as duas agremiações, disputado no campo do Paissandu, sendo anunciado outro entre o Rio Football e o time "Inglaterra" (A 
NOTÍCIA, 1902b, p. 3). Nesse ano, também foram disputadas outras partidas das agremiações, bem como entre os clubes de críquete e entre selecionados do Rio de Janeiro e de Niterói, bem como de paulistas e fluminenses. Agitava-se a cena futebolística da na época capital da República.

Portanto, a dinâmica dos primeiros momentos do futebol foi significativamente mais múltipla do que em muitas ocasiões é apresentada. Várias iniciativas foram ocorrendo simultaneamente, em geral desencadeadas pela experiência de gente da colônia britânica associada às agremiações de críquete. Mais ainda, a estruturação da modalidade tirou proveito do fato de que a sociedade fluminense, desde meados do século XIX, vinha desenvolvendo um gosto pelo esporte (MELO, 2001).

Uma notícia publicada no Jornal do Brasil nos permite vislumbrar que o futebol estava mesmo se tornando socialmente mais presente em várias esferas: "Queixam-se moradores da rua Barão do Flamengo de que essa rua está, à tarde e pela manhã, cheia de aficionados do jogo denominado football e o jogam de modo que chegam a quebrar as vidraças, como aconteceu com as do Hotel dos Estrangeiros" (JORNAL DO BRASIL, 1902, p. 2).

O bairro onde isso ocorreu, o Flamengo, se localiza nas redondezas dos campos nos quais jogavam as equipes lideradas por Oscar Cox (o "Brazil" que disputava partidas contra a "England"), o Rio Footballe o Fluminense. Isso pode ter sido um estímulo para novos praticantes. Voltamos ao terreno da especulação. São necessárias mais evidências para entender melhor esse princípio da difusão do futebol. Certamente são necessárias mais investigações ${ }^{22}$.

\section{CONCLUSÃO}

Toda pesquisa histórica tem algo de especulação. Deve, contudo, jamais perder de vista a evidência. A fonte, que não fala por si só, mas é prospectada a partir de operações teóricas e metodológicas, é que ancora o historiador em seu exercício profissional23.

No caso da História do Esporte, deve-se estar ainda mais atento a esse aspecto já que há grande número de informações circulando, produzidas em âmbitos distintos, esferas que têm pontos de contato e diálogo. Há que se tomar cuidado para não se reiterar afirmações sem que sejam mais bem investigadas, checadas, interpretadas.

Considerando a construção de uma história do ponto de vista acadêmico, sugere-se, inclusive, ser importante se perguntar sobre a utilidade de algumas informações, para além de um exercício de curiosidade. É nesse sentido que se chama a atenção para o debate sobre as "origens" do futebol. Mais do que saber quem foi ou não foi o "pioneiro", parece mais interessante entender os movimentos de gestação do "campo", um conjunto de ocorrências que acabam por ter desdobramentos futuros na conformação do fenômeno social. Esse esforço deve, obviamente, estar articulado com a compreensão do contexto em que se dá tal estruturação.

Esse foi 0 investimento que se procurou entabular neste artigo. Questionando a natureza de sustentação de algumas afirmações sobre os primórdios do futebol no Rio de Janeiro, tentou-se ajustar as análises a partir de novos olhares e evidências (isto é, tendo em conta que a descoberta de outros indícios pode alterar as reflexões sobre um objeto).

22 Alguns pesquisadores já se debruçaram sobre esse período inicial. Ver Pereira (2000), Santos (2010) e Souza (2015).

23 Esse é um tema largamente discutido na área de História. Para não ser extensivo, sugere-se Veyne (1982) e Ginzburg (1983). No caso específico da história do esporte, ver Booth (2005). 
O futebol não se desenvolveu de maneira alheia ao movimento esportivo que já estava em curso no Rio de Janeiro desde meados do século XIX. Nos dias de hoje, em boa medida, se forjou ao seu redor uma cultura específica, por vezes bastante distinta das outras modalidades. Na transição daquelas centúrias, todavia, isso ainda não era perceptível. Entender o ludopédio como parte dessa história, e não como um fenômeno separado e descolado, é uma postura fundamental.

Mais ainda, seu desenvolvimento teve relação com uma dinâmica específica, a das agremiações britânicas ligadas ao críquete que desde os anos 1850 estavam se organizando. Nesses espaços, o futebol foi uma das modalidades que integrou o culto a certa tradição, a valorização dos sports.

Isso significa que tenha surgido como um "esporte de elite"? Em alguma medida, sim, já que os clubes britânicos tinham certa tendência exclusivista. Não se tratava, contudo, somente de um corte de cariz econômico, embora esse aspecto também seja observável. Como eram iniciativas de um grupo ligado a uma nacionalidade, havia envolvida gente de estratos sociais médios que atuava nas empresas de propriedade de membros da colônia - fábricas têxteis, bancos, negócios comerciais, ferrovias -, companhias que participavam ativamente do movimento esportivo, inclusive com equipes e apoio financeiro.

Essa natureza de composição talvez possa ajudar a entender a rápida difusão do futebol. Aquela formação societária pode ter permitido certos encontros. Nas agremiações britânicas, entre os mais ricos e os de estrato médio. No cotidiano das empresas, entre os de estrato médio e os mais populares ${ }^{24}$. Além disso, o próprio fato de que os clubes de críquete foram se "abrasileirando" pode ter ajudado a impulsionar a popularização do ludopédio.

Essas últimas considerações são especulações que precisam ser mais bem investigadas a partir de novas evidências e pontos de vista conceituais. $O$ que se pode inferir com um pouco mais de precisão, por ora, é que, entre 1898 e 1902, há indícios de que o futebol começou a se desenvolver na cidade, foram realizados os primeiros jogos em diferentes esferas, se estruturou um pioneiro calendário e começou a se conformar um campo que iria rapidamente se estabelecer.

\section{REFERÊNCIAS}

BETHELL, Leslie. O Brasil no mundo. In: CARVALHO, José Murilo (Coord.). História do Brasil Nação (1808-2010). Rio de Janeiro: Objetiva, 2012. v. 2: A construção nacional (1830-1889). p. 131-178.

BOOTH, Douglas. The field: truth and fiction in sport history. Londres: Routledge, 2005.

THE BRAZILIAN Review, 11 mar. 1902a, p. 130.

THE BRAZILIAN Review, 2 set. 1902b, p. 434.

CORREIO da Manhã, 22 set. 1901, p. 3.

CORREIO da Manhã, 12 jul. 1902a, p. 3.

24 Esse aspecto fica claro no caso da experiência do Bangu Athletic Club, fundado em 1904. Ver SANTOS JUNIOR, Nei Jorge dos. A construção do sentimento local: o futebol nos arrabaldes de Bangu e Andaraí (1914-1923). Dissertação (Mestrado em História Comparada) - Instituto de História, Universidade Federal do Rio de Janeiro, Rio de Janeiro, 2012. 
CORREIO da Manhã, 19 ago. 1902b, p. 3.

DIÁRIO de Notícias, 2 out. 1888, p. 2.

FONSECA, Vitor Manoel Marques da. No gozo dos direitos civis: associativismo no Rio de Janeiro, 1903-1916. Niterói: Muiraquitã, 2008.

FREYRE, Gilberto. Ingleses no Brasil. 2. ed. Rio de Janeiro: José Olympio, 1977.

GAZETA de Notícias, 23 mar. 1891, p. 1.

GAZETA de Notícias, 12 maio 1901, p. 3.

GAZETA de Petrópolis, 17 out. 1899, p. 3.

GINZBURG, Carlo. Chaves do Mistério: Morelli, Freud e Sherlock Holmes. In: ECO, Humberto; SEBEOK, Thomas A. $O$ signo de três. São Paulo: Perspectiva, 1983. p. 89-129.

O GLOBO, 5 dez. 1882, p. 2.

HISTÓRIA do futebol no Rio de Janeiro. Disponível em: <https://pt.wikipedia.org/wiki/ Hist\%C3\%B3ria do futebol do Rio de Janeiro>. Acesso em: 29 mar. 2016.

IORIO, Vitor; IORIO, Patrícia. Rio Cricket e Associação Atlética: mais de um século de paixão pelo esporte. Rio de Janeiro: Arte Ensaio, 2008.

JORNAL do Brasil, 30 nov. 1891, p. 2.

JORNAL do Brasil, 5 set. 1902, p. 2.

JORNAL do Commercio, 16 jun. 1894, p. 3.

JORNAL do Commercio, 8 mar. 1899, p. 2.

JORNAL do Commercio, 21 jun. 1898, p. 2.

LUCA, Tânia Regina de. História dos, nos e por meio dos periódicos. In: PINSKY, Carla Bassanezi (Org.). Fontes históricas. São Paulo: Contexto, 2005. p. 111-153.

MARINHO, Inezil Penna. Contribuição para a história do futebol no Brasil. Arquivos da ENEFD, v. 9 , n. 10 , p. 41-45, nov./dez. 1956.

MAZZONI, Tomás. História do Futebol no Brasil (1894-1950). São Paulo: Leia, 1950.

MELO, Victor Andrade de. Cidade sportiva: primórdios do esporte no Rio de Janeiro. Rio de Janeiro: Relume Dumará, 2001.

MELO, Victor Andrade de. Das touradas às corridas de cavalo e regatas: primeiros momentos da configuração do campo esportivo no Brasil. In: DEL PRIORE, Mary; MELO, Victor Andrade de (Org.). História do esporte no Brasil: do Império aos dias atuais. São Paulo: Editora Unesp, 2009a. p. 35-70.

MELO, Victor Andrade de. Corpos, bicicletas e automóveis: outros esportes na transição dos séculos XIX e XX. In: DEL PRIORE, Mary; MELO, Victor Andrade de (Org.). História do esporte no Brasil: do Império aos dias atuais. São Paulo: Editora Unesp, 2009b. p. 71-105. 
MELO, Victor Andrade de. Antes do club: as primeiras experiências esportivas na capital do Império (1825-1851). Projeto História, v. 49, p. 197-236, abr. 2014.

MELO, Victor Andrade de. A sociabilidade britânica: os clubes de cricket no Rio de Janeiro do século XIX. Rio de Janeiro: PPGHC, 2016.

A NOTÍCIA, 16 e 17 ago. 1902a, p. 2.

A NOTÍCIA, 20 e 21 ago. 1902b, p. 3.

PEREIRA, Leonardo Affonso de Miranda. Footballmania: uma história social do futebol no Rio de Janeiro. Rio de Janeiro: Nova Fronteira, 2000.

REVISTA Brasileira, jul./set. 1896, p. 319.

RICUPERO, Rubens. O Brasil no mundo. In: SILVA, Alberto da Costa (Coord.). História do Brasil Nação (1808-2010). Rio de Janeiro: Objetiva, 2011. v. 1: Crise colonial e independência (1808-1830). p. 115-160.

THE RIO News, 23 abr. 1895, p. 5.

THE RIO News, 20 jul. 1897, p. 4.

THE RIO News, 14 jun. 1898b, p. 5.

THE RIO News, 16 ago. 1898c, p. 8.

THE RIO News, 14 jun. 1898, p. 5.

THE RIO News, 2 maio 1899, p. 4.

THE RIO News, 25 jun. 1901, p. 5.

ROCHA, Antonio Penalves. The Rio News de A. J. Lamoureux: um jornal abolicionista carioca de um norte-americano. Projeto História, n. 35, p. 141-159, dez. 2007.

SANTOS, João Manuel Casquinha Malaia. Revolução Vascaína: a profissionalização do futebol e inserção socioeconômica de negros e portugueses na cidade do Rio de Janeiro (19151934). 2010. 489 f. Tese (Doutorado em História Econômica) - Faculdade de Filosofia, Letras e Ciências Humanas, Universidade de São Paulo, São Paulo, 2010.

SANTOS, João Manuel Casquinha Malaia, DRUMOND, Maurício. A construção de histórias do futebol no Brasil (1922 a 2000): reflexões. Tempo, v. 19, n. 34, p. 19-31, jun. 2013.

SOUZA, Fabiana Fátima Dias de. 0 professor da moda: Arthur Higgins e a Educação Física no Brasil (1885-1934). 2011. 136 p. Dissertação (Mestrado em Educação Física) - Faculdade de Educação Física, Universidade Federal de Juiz de Fora, Juiz de Fora, 2011.

SOUZA, Glauco José Costa. "O football nós podemos jogar": uma análise sobre o desenvolvimento do futebol fora dos clubes da elite do Rio de Janeiro. Recorde, v. 8, n. 2, p. 1-28, jul./dez. 2015.

SPORT Náutico (Revista da Semana), 3 ago. 1902, p. 433.

VEYNE, Paul. Como se escreve a História. Brasília: Editora UNB, 1982. 


\section{Apoio:}

CNPq. Faperj 